\title{
Prospective observational study on predicting adverse clinical outcomes in patients with implanted defibrillating devices - a study rationale, design and principal methods
}

\author{
Przemysław Guzik', Jarosław Piskorski², Henryk Wysocki', Andrzej Wykrętowicz' \\ ${ }^{1}$ Department of Cardiology - Intensive Therapy, Poznan University of Medical Sciences, Poland \\ 2 Institute of Physics, University of Zielona Gora, Poland
}

\begin{abstract}
The project "Predicting adverse clinical outcomes in patients with implanted defibrillating devices" is a prospective observational study in a group of high risk cardiac patients with already implanted either an implantable cardioverter-defibrillator (ICD) or a cardiac resynchronization therapy device with defibrillating mode (CRT-D). The primary project aim is to build predictive models for an appropriate ICD or CRT-D interventions and other adverse clinical outcomes based on clinical assessment of the cardiovascular system, general clinical status, advanced mathematical and statistical analysis of cardiovascular time series and biological signals, including pressure waveforms, ECG and cardiac impedance. Up to 600 ambulatory adult patients are scheduled to be enrolled and after the first visit they are expected to be followed-up every 6 months for a number of clinical outcomes, including antiarrhythmic therapy intervention, sudden and aborted cardiac death and total mortality. The project launched in March 2010 and is expected to end in February 2014.
\end{abstract}

Key words: cardiac resynchronization therapy; implantable cardioverter-defibrillator; risk prediction; sudden cardiac death; ventricular arrhythmia.

\section{General information}

The project "Predicting adverse clinical outcomes in patients with implanted defibrillating devices" was awarded a research grant from the Foundation for Polish Science from Warsaw, Poland, in the 4th edition of the TEAM competition in February 2010. The contract between the Foundation for Polish Science (FPS) and Poznan University of Medical Sciences (PUMS) in Poznan, Poland, was signed on the $1^{\text {st }}$ of March 2010, and the duration of the project was planned for 48 months, until the $28^{\text {th }}$ of February 2014.

This project is a prospective observational study in a group of high risk cardiac patients with already implanted either an implantable cardioverter-defibrillator (ICD) or a cardiac resynchronization therapy device with defibril- lating mode (CRT-D). The patients should have survived a myocardial infarction and/or suffered from chronic heart failure with severely depressed left ventricular (LV) function with ejection fraction (LVEF) of no more than 35\% at the time of ICD or CRT-D implantation, or be survivors of sudden cardiac arrest with implanted ICD or CRT-D, or suffer from cardiac diseases with an increased risk of premature death like hypertrophic cardiomyopathy, LQT syndrome or Brugada syndrome. The project addresses the field of electrotherapy with implantable cardioverter-defibrillators (ICD or CRT-D) which main (ICD) or one of main (CRT-D) functions is the application of electrotherapy for the treatment of life threatening ventricular arrhythmias like ventricular tachycardia (VF) or ventricular fibrillation (VF). The electrotherapy is applied in a form of antitachycardia pacing that is faster than VT or energy discharge 
by intrathoracic defibrillating electrode to stop VT/VF. The project is interdisciplinary in nature and requires a close co-operation of specialists in medicine, engineering, software development, and basic science.

\section{Management}

Principal Investigator: Associate Professor Przemyslaw Guzik from PUMS.

Co-investigators: Associate Professor Jaroslaw Piskorski from University of Zielona Gora in Poland, Professor Andrzej Wykretowicz from PUMS and Professor Henryk Wysocki from PUMS.

International partners: Professor Georg Schmidt from Klinikum rechts der Isar, 1. Medizinische Klinik, Technische Universitat Munchen, Munich, Germany; Professor Adrian Baranchuk from Department of Cardiac Electrophysiology and Pacing at the Kingston General Hospital of the Queen's University in Kingston, ON, Canada; Professor Wojciech Zareba from Heart Research Centre, University of Rochester Medical Center, Rochester, NY, USA; Professor Marek Malik Cardiac Electrophysiology at the University of London, Head of Non-Invasive Electrophysiology unit at St. George's, London, UK.

\section{Ethics}

Bioethical Committee at Poznan University of Medical Sciences on 10th April 2010 accepted all project's protocols and forms, including information for patients and the form of their consent for study participation and withdrawal. The permission number is 363/10.

\section{Finance}

The total value of granted funds is 1,520,000.00 Polish Zloty which at the time of contract signing amounted to nearly $390,000.00$ Euro. The funds were designed for research stipends for 3 medical students, $3 \mathrm{PhD}$ students and one post-doc - all of them had to be recruited from open calls. Additionally, funds were earmarked to purchase new equipment, tools and software, cover the costs of biochemical analysis, domestic and international exchange, promotion of study results and publications as well as for work remuneration.

\section{Research Basic Concept}

Devices such as ICD and CRT-D save lives in high risk cardiac conditions like post-infarction, non-ischemic heart failure, in survivors of sudden cardiac death secondary to VT/VF, hypertrophic cardiomyopathy, long QT syndrome or Brugada syndrome [1-3]. There are thousands of people with implanted defibrillating devices worldwide and all these patients have created a new clinical population since ICD and CRT-D have been implanted. Only a minority of such patients have appropriate lifesaving intervention and for this reason the numbers of patients needed to treat in order to save one life is quite high. Based on the established criteria for ICD/CRT-D implantation, it is necessary to implant an ICD or CRT-D to several patients to save one life - the number needed to treat patients with such a device depends on the duration of follow up [1-3]. Based on the MADIT II trial results this number was 133 after 1 year, and substantially dropped to 17 after 2 years and to 8 the end of a 3-year follow-up [4-6]. These figures show that early criteria proposed for ICRD and CRT-D implantation before 2010, when this project was launched, for the identification of high risk patients, were not effective.

Numbers of studies attempted to establish optimal systems of identification high-risk patients. These studies, however, compared ICD/CRT-D with placebo or pharmacological antiarrhythmic therapy or CRT-D vs CRT alone (CRT without defibrillating mode). However, before 2010 not a single prospective study focused on patients with already implanted defibrillating devices. Our study hypothesis was that it is possible to improve the identification of high-risk patients eligible for ICD or CRT-D implantation based on a non-invasive assessment of the cardiovascular status and general patient condition.

\section{Research Project Objectives}

The study primary objective is to build various predictive models for an appropriate ICD or CRT-D interventions and other adverse clinical outcomes. The models will be based on both detailed and wide clinical assessment of the cardiovascular system, general clinical status, and modern advanced mathematical and statistical analysis for cardiovascular time series and biological signals as pressure waveforms, ECG and cardiac impedance waves. The study secondary objective is to develop software and tools for the analysis of the variability and asymmetry of cardiovascular time series, for the detailed analysis of the ECG structure and arterial pressure waveforms mechanical properties.

\section{Research Plan}

Ambulatory patients with already implanted ICD or CRT-D and who fulfill the project's inclusion criteria (Table 
1) will undergo a detailed non-invasive clinical examination with biochemical analysis of their venous blood and urine samples. Patients will be followed-up every 6 months during their routine visits at our out-patient clinic or, in case of a missing visit, by phone or mail. During each visit the current status of the implanted device will be routinely checked by telemetry and all events (arrhythmias, interventions), if recorded by the device, will be transferred and stored for further analysis.

\section{Research methodology}

\section{Study population}

Up to 600 patients after an elective implantation of ICD or CRT-D, which were in agreement with the most current guidelines and recommendations for an implantation of a respective device. Summary of eligible patients is shown in Table 1.

\section{Methods}

All patients will undergo the following methodological approach:

- history taking, physical examination and anthropometrics, including body composition analysis;

- functional cardiovascular evaluation with the 4-degree New York Heart Association functional class, echocardiography, the 6-minute walking test, cardiac impedance, arterial photoplethysmography and applanation tonometry [7-15];

- structural cardiovascular evaluation of carotid arteries, aorta and the heart with ultrasound methods $[8$, 9, 11, 13];

- measurement of indices of autonomic modulation of the cardiovascular system, and cardiovascular variability, including variability and asymmetry of haemodynamics parameters, heart rate and blood

Table 1. Eligibility and inclusion criteria for patients enrolled to the project "Predicting adverse clinical outcomes in patients with implanted defibrillating devices"

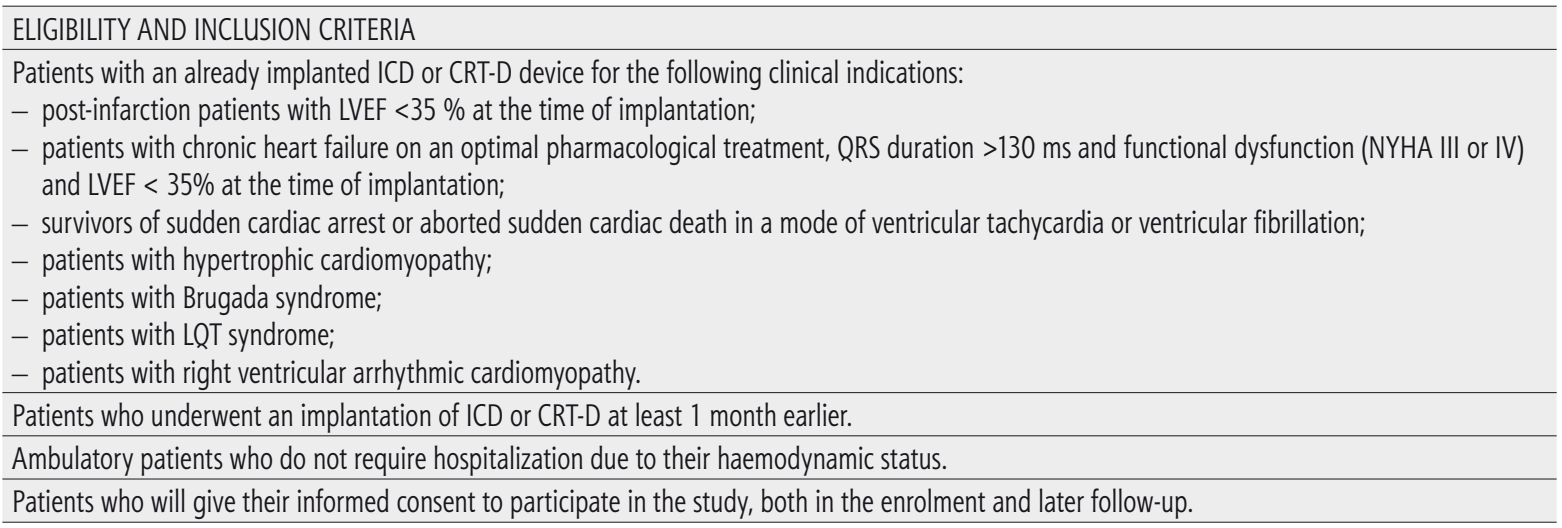

Table 2. Clinical outcomes of the project

\begin{tabular}{l} 
PRIMARY OUTCOMES \\
1. Mortality of any cause; \\
2. Fatal sudden cardiac death, aborted sudden cardiac death or sudden cardiac arrest; \\
3. Appropriate antiarrhythmic therapy of discharge of the ICD or CRT-D; \\
4. Combination of $2 \& 3$; \\
5. Combination of $1 \& 3$. \\
SECONDARY OUTCOMES \\
1. Hospitalization due to advancing heart failure; \\
2. Death related to heart failure aggravation; \\
3. Non-cardiac death; \\
4. Recurrent arrhythmic events defined as: an appropriate antiarrhythmic therapy of discharge of the ICD or CRT-D, or aborted sudden cardiac death, \\
or sudden cardiac arrest; \\
5. Electrical storm defined as at least 3 appropriate antiarrhythmic therapy of discharge of ICD or CRT-D during 24 hours with at least 1 minute gap \\
between each; \\
6. Syncope of any cause; \\
7. Syncope of an unknown cause; \\
8. Combination of fatal sudden cardiac death, aborted sudden cardiac death or sudden cardiac arrest or an appropriate antiarrhythmic therapy of \\
discharge of ICD or CRT-D, or syncope of an unknown cause. \\
\hline
\end{tabular}


pressure variability and asymmetry, arterial baroreflex function [16-27];

- biochemistry of fasting blood and urine samples for NT-pro-BNP (N-terminal prohormone of brain natriurectic peptide) and standard clinical biochemical parameters [28-29].

All data will be collected in the dedicated database-analytical system Granary (www.OpenGranary. com, version 2.3, Poland).

Statistical analysis - basic and advanced for building multivariate models predicting an appropriate antiarrhythmic intervention and other clinical outcomes defined in Table 2.

\section{Expected results}

According to existing publications we expect that some of the variables like very low left ventricular ejection fraction, increased end-diastolic diameter of the left ventricle, reduced deceleration capacity, the distance covered during the 6-minute walking test, the increased C-reactive protein, NT-pro-BNP, creatinine or mean resting heart rate will have a significant association with adverse clinical outcomes. However, in this study we plan to analyse many more variables which have never been studied in patients with implanted defibrillating devices. Moreover, we intend to build several predictive models starting from the simplest possible, to the minimal number of included variables, the cheapest to put into practice and ending with the most sophisticated and most precise in identification of high risk patients. All of the models will be published and available for free in a variety of ways, like e.g. stand-alone programs or Excel macros. We hope that with the obtained models we will be able to identify more precisely than it is possible now the highrisk patients who need an extra medical attention and treatment like invasive electrophysiological ablation of the heart. We also hope that with the identification of low-risk patients it will be easier to re-define some indications for ICD or CRT-D implantations and thus, finally, further reduce the costs of implantation procedures.

We plan to develop software for the analysis of the variability and asymmetry of various cardiovascular time series like heart rate, blood pressure, stroke volume, cardiac output or vascular resistance. We also intend to develop another software for the pressure waveform analysis and check the clinical value of obtained quantitative parameters. Finally, we want to develop the software for a detailed analysis of digital
ECG and apply mathematical, physical and statistical algorithms to study its clinical utility.

We also assume that with the collected data from all patients with huge number of parameters and outcomes we will built our own database for big data analysis.

\section{Acknowledgement}

This work is a part of the project "Predicting adverse clinical outcomes in patients with implanted defibrillating devices," which was supported by the Foundation for Polish Science-TEAM program co-financed by the European Union within the European Regional Development Fund.

\section{References}

1. Zipes DP1, Camm AJ, Borggrefe M, Buxton AE, Chaitman B, Fromer $\mathrm{M}$ et al. American College of Cardiology; American Heart Association Task Force; European Society of Cardiology Committee for Practice Guidelines; European Heart Rhythm Association; Heart Rhythm Society. ACC/AHA/ESC 2006 guidelines for management of patients with ventricular arrhythmias and the prevention of sudden cardiac death: a report of the American College of Cardiology/American Heart Association Task Force and the European Society of Cardiology Committee for Practice Guidelines (Writing Committee to Develop guidelines for management of patients with ventricular arrhythmias and the prevention of sudden cardiac death) developed in collaboration with the European Heart Rhythm Association and the Heart Rhythm Society. Europace. 2006;8:746-837.

2. Dickstein K, Vardas PE, Auricchio A, Daubert JC, Linde C, McMurray J et al. ESC Committee for Practice Guidelines (CPG). 2010 Focused Update of ESC Guidelines on device therapy in heart failure: an update of the. 2008 ESC Guidelines for the diagnosis and treatment of acute and chronic heart failure and the. 2007 ESC guidelines for cardiac and resynchronization therapy. Developed with the special contribution of the Heart Failure Association and the European Heart Rhythm Association. Eur Heart J. 2010;31:2677-87.

3. Brignole $M$, Auricchio A, Baron-Esquivias G, Bordachar P, Boriani G, Breithardt OA et al. 2013 ESC Guidelines on cardiac pacing and cardiac resynchronization therapy: the Task Force on cardiac pacing and resynchronization therapy of the European Society of Cardiology (ESC). Developed in collaboration with the European Heart Rhythm Association (EHRA). Eur Heart J. 2013;34:22812329.

4. Salukhe T, Dimopoulos K, Sutton R, Coats A, Piepoli M, Francis $D$. Life-years gained from defibrillator implantation: markedly non-linear increase during 3 years of follow-up and its implications. Circulation. 2004;109: 1848-53.

5. Camm J, Klein H, Nisam S. The cost of implantable defibrillators: perceptions and reality. Eur Heart J. 2007;28:392-7. 
6. Tung R, Zimetbaum P, Josephson ME. A critical appraisal of implantable cardioverter-defibrillator therapy for the prevention of sudden cardiac death J Am Coll Cardiol. 2008;52:1111-21.

7. Rasekaba T, Lee AL, Naughton MT, Williams TJ, Holland AE. The six-minute walk test: a useful metric for the cardiopulmonary patient. Intern Med J. 2009;39:495-501.

8. Cavalcante JL, Lima JA, Redheuil A, Al-Mallah MH. Aortic stiffness: current understanding and future directions. J Am Coll Cardiol. 2011;57:1511-22.

9. Nagueh SF, Appleton CP, Gillebert TC, Marino PN, Oh JK, Smiseth $O A$ et al. Recommendations for the evaluation of left ventricular diastolic function by echocardiography. Eur J Echocardiogr. 2009;10:165-93.

10. Thygesen K, Alpert JS, Jaffe AS, Simoons ML, Chaitman BR, White HD; Joint ESC/ACCF/AHA/WHF Task Force for Universal Definition of Myocardial Infarction. Third universal definition of myocardial infarction. J Am Coll Cardiol. 2012;60:1581-98.

11. Lang RM, Bierig $M$, Devereux RB, Flachskampf FA, Foster E, Pellikka PA et al. American Society of Echocardiography's Nomenclature and Standards Committee; Task Force on Chamber Quantification; American College of Cardiology Echocardiography Committee; American Heart Association; European Association of Echocardiography, European Society of Cardiology. Recommendations for chamber quantification. Eur J Echocardiogr. 2006;7:79-108.

12. Jiamsripong P, Honda T, Reuss CS, Hurst RT, Chaliki HP, Grill DE et al. Three methods for evaluation of left atrial volume. Eur J Echocardiogr. 2008;9:351-5.

13. Wykretowicz A, Gerstenberger P, Guzik P, Milewska A, Krauze T, Adamska $K$ et al. Arterial stiffness in relation to subclinical atherosclerosis. Eur J Clin Invest. 2009;39:11-6.

14. Douglas PS. The left atrium: a biomarker of chronic diastolic dysfunction and cardiovascular disease risk. J Am Coll Cardiol. 2003;42:1206-7.

15. Fieselmann JF, Hendryx MS, Helms CM, Wakefield DS. Respiratory rate predicts cardiopulmonary arrest for internal medicine patients, J Gen Intern Med. 1993;8:35460.

16. Bauer A, Guzik P, Barthel P, Schneider R, Watanabe MA, Schmidt $G$. Reduced prognostic power of ventricular late potentials in post-infarction patients of the reperfusion era. Eur Heart J. 2005; 26: 755-61.

17. Bauer A, Malik M, Schmidt G, Barthel P, Bonnemeier $\mathrm{H}, \mathrm{Cyg}$ ankiewicz I et al. Heart rate turbulence: standards of measurement, physiological interpretation, and clinical use: International Society for Holter and Noninvasive Electrophysiology Consensus. J Am Coll Cardiol. 2008;52:1353-65.

18. Guzik P, Piskorski J, Krauze T, Wykretowicz A, Wysocki H. Heart rate asymmetry by Poincaré plots of RR intervals. Biomed Tech (Berl). 2006;51:272-5.
19. Piskorski J, Guzik P. Geometry of the Poincaré plot of RR intervals and its asymmetry in healthy adults. Physiol Meas. 2007;28:287-300.

20. Guzik P, Piskorski J, Krauze T, Wykretowicz A, Wysocki $\mathrm{H}$. Partitioning total heart rate variability. Int J Cardiol. 2010;144: 138-9.

21. Guzik P, Rogacka D, Tarchalski J, Minczykowski A, Baliński $M$, Wykrętowicz $A$ et al. Comparison of the exercise treadmill test and 24-hour ECG Holter monitoring in patients with syndrome $X$ or coronary atherosclerosis. Kard Pol. 2007;3:262-9.

22. Katarzynska-Szymanska A, Ochotny R, Oko-Sarnowska Z, Wachowiak-Baszynska H, Krauze T, Piskorski J et al. Shortening baroreflex delay in hypertrophic cardiomyopathy patients - an unknown effect of $\beta$-blockers. $\mathrm{Br} J \mathrm{Clin}$ Pharmacol. 2013;75:1516-24.

23. Piskorski J, Guzik P. Compensatory properties of heart rate asymmetry. J Electrocardiol. 2012;45:220-4.

24. Piskorski J, Guzik P. Asymmetric properties of long-term and total heart rate variability. Med Biol Eng Comput. 2011;49:1289-97.

25. Guzik P, Piskorski J, Barthel P, Bauer A, Müller A, Junk N et al. Heart rate deceleration runs for postinfarction risk prediction. J Electrocardiol. 2012;45:70-6.

26. Piskorski J, Guzik P. The structure of heart rate asymmetry: deceleration and acceleration runs. Physiol Meas. 2011;32:1011-23.

27. Guzik P, Piskorski J, Krauze T, Narkiewicz K, Wykretowicz A, Wysocki H. Asymmetric features of short-term blood pressure variability. Hypertens Res. 2010;33:1199-1205.

28. Januzzi JL Jr, Rehman SU, Mohammed AA, Bhardwaj A, Barajas L, Barajas J et al. Use of amino-terminal pro-Btype natriuretic peptide to guide outpatient therapy of patients with chronic left ventricular systolic dysfunction. J Am Coll Cardiol. 2011;58: 1881-89.

29. Scott PA, Barry J, Roberts PR, Morgan JM. Brain natriuretic peptide for the prediction of sudden cardiac death and ventricular arrhythmias: a meta-analysis. Eur J Heart Fail. 2009;11:958-66.

Correspondence address: Przemyslaw Guzik, MD, PhD, FESC, ISHNE Fellow Department of Cardiology-Intensive Therapy and Internal Medicine Poznan University of Medical Sciences Przybyszewskiego 49 Street 60-355 Poznan, Poland phone: +48618691391 fax: +48618691391 email: pguzik@ptkardio.pl 